\title{
A new general index of home range overlap and segregation: the Lesser Kestrel in Southern Italy as a case study
}

\author{
Alessandro Ferrarini* ${ }^{*}$, Giuseppe Giglio, Stefania Caterina Pellegrino and Marco Gustin
}

\begin{abstract}
Background: There is increasing interest in evaluating home-range overlap (or, otherwise, segregation) between bird species, and between or within bird populations, to inform spatial planning. So far, studies of home-range overlap typically make use of comparisons between pairs of individuals, populations or species, and return a matrix of pairwise overlaps (e.g., percent overlaps). However, when the number of individuals, populations or species to be compared is elevated, an overlarge overlap matrix is difficult to interpret from an ecological viewpoint.

Methods: We propose here a new, conceptually simple and computationally efficient index (general overlap index; $\mathrm{GO}$ ) for the ready computation within GIS of home range overlap of an arbitrarily large number (i.e., $n \geq 2$ ) of individuals, populations or species. Whatever the number of home ranges to be compared, $\mathrm{GO}$ l always returns a single score between 0 and 100. As a case study, we applied our index to 24,074 GPS points of 10 Lesser Kestrels (Falco naumanni) in order to estimate within-colony and between-colony overlaps in two neighboring colonies in Southern Italy.

Results: Within-colony overlap was elevated for both colonies ( $96.41 \%$ at Cassano delle Murge, $n=5$ individuals; 81.38\% at Santeramo in Colle, $n=5$ individuals), while between-colony overlap was low (19.12\%; $n=2$ colonies) and, after a randomization procedure, more spatially-segregated than expected by chance.

Conclusions: Modern biotelemetry offers huge amounts of data describing the space use of animal species. The use of intuitive and straightforward indices, like $\mathrm{GO}$, can be useful to promptly extract ecological information from such an amount of data (e.g. detecting change in space use over successive years, evaluating the reliability of various home-range estimators).
\end{abstract}

Keywords: Between-colony overlap, Falco naumanni, Home range randomization, Overlap estimator, Spatial segregation, Within-colony overlap

\section{Background}

Intraspecific and interspecific interactions impact the extent and spatial patterning of animal home ranges (Adams 2001). Animals compete for resources (e.g. food, shelter and mates) and it has long been known (e.g., Brown and Orians 1970; Davies 1978; Newton 1998) that one way to compete is to exclude potential competitors

${ }^{*}$ Correspondence: sgtpm@libero.it

Conservation Department, LIPU - BirdLife Italy (Lega Italiana Protezione

Uccelli), Via Udine 3/a, 43122 Parma, Italy from the area containing resources. Overlap, or otherwise segregation, between bird species (Warning and Benedict 2015; Zhao et al. 2015), and between or within bird populations (Yang et al. 2011; Clay et al. 2016) has been progressively recorded in recent years due to the increased availability of telemetry data (Wang et al. 2010). The increasing popularity of multi-species studies in the context of spatial management (e.g. Lascelles et al. 2016) has enhanced the need to calculate home range overlap for a large number of individuals, populations or species. 
Home-range overlap indices have several important applications to wildlife research and management. Overlap indices can be useful for assessing the degree of interaction among individuals as well as site fidelity for a particular individual. In addition, overlap measures may be used to measure the reliability of various home-range estimators (Fieberg and Kochanny 2005). There are several overlap indices available in the literature (Kernohan et al. 2001). The available approaches make use of comparisons between pairs of individuals, populations or species, and return a matrix of pairwise overlaps. The most common and intuitive approach is percent overlap, i.e. the proportion of animal $i$ 's home range that is overlapped by animal $j$ 's home range (Kernohan et al. 2001). However, when the number of individuals, populations or species to be compared is elevated, an overlarge overlap matrix is difficult to interpret from an ecological viewpoint. For example, with only 10 individuals (populations, or species), a $10 \times 10$ pairwise overlap matrix is produced, whose ecological interpretation could be not that simple. Researchers have interpreted multiple pairwise comparisons using mean overlaps (e.g., Macias-Duarte and Panjabi 2013), however mean values can be scarcely representative of the pairwise overlap matrix if the dispersion of overlap values around the mean is elevated.

Accordingly, we propose here a new, conceptually simple and computationally efficient index (general overlap index; GOI hereafter) for the ready computation within GIS of home range overlap of an arbitrarily large number (i.e., $n \geq 2$ ) of individuals, populations or species. As a case study, we applied our index to ten Lesser Kestrels (Falco naumanni) in order to estimate within-colony and between-colony overlap/segregation in two neighboring urban colonies (Cassano delle Murge and Santeramo in Colle; Apulia region) in Southern Italy. From an ecological point of view, it was a good study system to investigate competition during the breeding season as the two colonies represent the most elevated density of Lesser Kestrels in urban areas worldwide (Gustin et al. 2013).

The Lesser Kestrel is a colonial, small falcon breeding in steppe-like grasslands and cultivated landscapes with short vegetation and extensive crops (BirdLife International 2017). It is present among Annex I species of EU Wild Birds Directive (2009/147/EEC), and its important breeding habitats have been designated as Special Protection Areas of the Natura 2000 Network. In Southern Italy, the Lesser Kestrel has been widely studied in the nearby colonies of Gravina in Puglia and Altamura (Gustin et al. 2014a, b, 2017a; Gustin et al. 2014b, 2017b, 2018; Ferrarini et al. 2018a, b; Ferrarini et al. 2018b, 2019). The study area (Fig. 1) is an agricultural landscape located within the SPA (Special Protection Area) "Murgia Alta" IT9120007, and also included within the IBA (Important Bird Area) "Murge".

\section{Methods}

We monitored ten birds ( 5 at Cassano delle Murge and 5 at Santeramo in Colle; Table 1) during the nestling period (Additional file 1: Fig. S1) in the two urban colonies of Cassano delle Murge (between June 22th and July 6th 2017; 11,993 GPS points) and Santeramo in Colle (between June 13th and June 29th 2017; 12,081 GPS points) where Lesser Kestrels have their artificial nests (Additional file 1: Fig. S2). We tracked birds using TechnoSmart GiPSy-4 and GiPSy-5 data loggers $(23 \times 15 \times 6 \mathrm{~mm}, 5 \mathrm{~g}$ weight; Additional file 1: Fig. S3), which provided information about date, time, latitude, longitude, altitude ( $\mathrm{m}$ a.s.l.) and instantaneous speed $(\mathrm{m} / \mathrm{s})$. GPS sampling frequency was one fix every three minutes. We fitted birds with data loggers at their nest boxes when they were delivering food to nestlings. All devices were tied dorsally to the base of two central tail feathers (Additional file 1: Fig. S4). The weight of the devices in relation to that of the birds was less than $4 \%$ for all individuals. The attachment of transmitters did not take more than $15 \mathrm{~min}$, and had no visible deleterious effects on the birds. To download the data from the data-loggers, we recaptured birds at their nest boxes.

We imported GPS data into GIS and estimated the individual home ranges using the fixed-mean minimum convex polygons (Kenward 1987) which calculates the arithmetic mean of all $X$ (longitude) and $Y$ (latitude) coordinates, then selects the requested percentage of points closest to that arithmetic mean point. We also estimated colony-specific home ranges (i.e. home ranges calculated after pooling the locations of all individuals of each colony). We chose the $95 \%$ isopleth to represent home range as this value is widely used in the literature (White and Garrott 1990).

In order to quantify home range overlaps, we first used the most common method (percent overlap; Kernohan et al. 2001), i.e. $H R_{i, j}=100 \times A_{i, j} / A_{i}$, where $H R_{i, j}$ is the proportion of home-range $i$ that is overlapped by home-range $j, A_{i}$ is the area of home-range $i$, and $A_{i, j}$ is the area of overlap between the two homeranges. As $H R_{i, j} \neq H R_{j, i}$ (i.e., directional indices), we quantified the degree of overlap using both $H R_{i, j}$ and $H R_{j, i}$. In addition, we also employed our general overlap index $(G O I)$. In the case of perfectly disjoint (i.e. non-overlapping) home ranges (Fig. 2a), the total area $\left(A_{T}\right)$ covered by the home ranges is simply the sum of their extents (i.e. $\sum A_{i}$ ). In the case of perfectly nested (i.e. overlapping) home ranges (Fig. 2b), $A_{T}$ is simply 


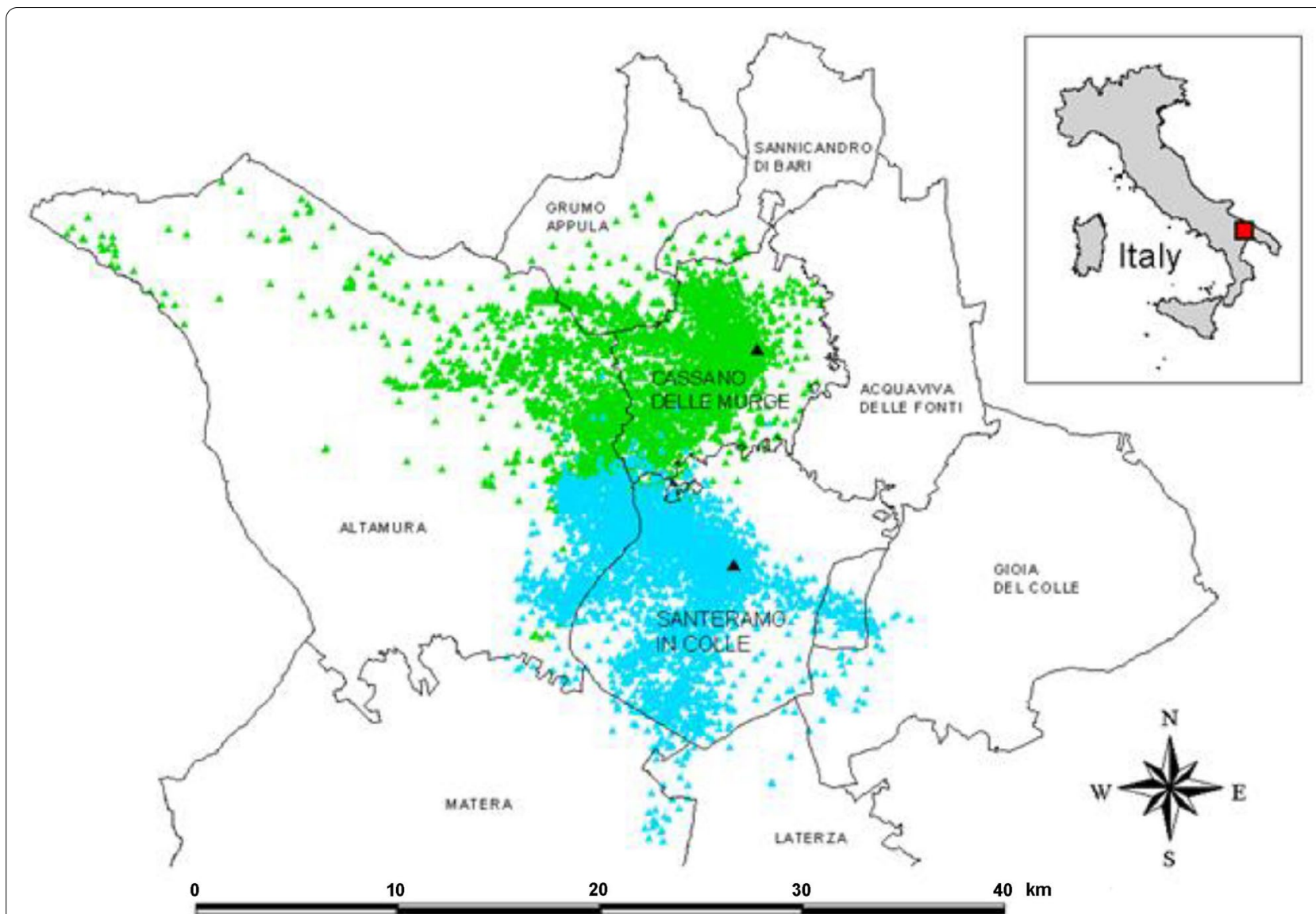

Fig. 1 Study area (Apulia, Italy). Municipalities (outlined in black) and GPS points of the two Lesser Kestrel's colonies under study (Cassano delle Murge, green points; Santeramo in Colle, blue points) are shown. The two black triangles indicate the two urban colonies where the nests of the tracked Lesser Kestrels are located

Table 1 Description of the tracked Lesser Kestrels

\begin{tabular}{llllllrr}
\hline GPS ID & Colony & Sex & Weight (g) & Start date of tracking & End date of tracking & $\begin{array}{l}\text { No. of GPS } \\
\text { points }\end{array}$ & $\begin{array}{l}\text { Home range } \\
\text { size (ha) }\end{array}$ \\
\hline F6 C & Cassano delle Murge & F & 138 & June 30th 2017 & July 5th 2017 & 1920 & $21,142.96$ \\
M6C & Cassano delle Murge & M & 135 & June 30th 2017 & July 1st 2017 & 509 & 3802.39 \\
F12C & Cassano delle Murge & F & 159 & June 29th 2017 & July 6th 2017 & 3185 & $14,324.96$ \\
F15 C & Cassano delle Murge & F & 128 & June 29th 2017 & July 6th 2017 & 3011 & 7304.12 \\
M15 C & Cassano delle Murge & M & 128 & June 22th 2017 & June 30th 2017 & 3368 & 9072.23 \\
M4 S & Santeramo in Colle & M & 124 & June 16th 2017 & June 22th 2017 & 2765 & $11,147.12$ \\
F18 S & Santeramo in Colle & F & 155 & June 13th 2017 & June 16th 2017 & 1375 & 2275.81 \\
M18 S & Santeramo in Colle & M & 135 & June 13th 2017 & June 16th 2017 & 1417 & 4046.01 \\
F24 S & Santeramo in Colle & F & 120 & June 22th 2017 & June 29th 2017 & 3311 & 3431.67 \\
M24 S & Santeramo in Colle & M & 116 & June 22th 2017 & June 29th 2017 & 3213 & 9762.25 \\
\hline
\end{tabular}

the extent of the largest home range (i.e. $\left.\max \left(A_{\mathrm{i}}\right)\right)$. In the intermediate case (i.e., partially overlapping home ranges; Fig. 2c), $A_{T}$ corresponds to the union of the home range polygons (i.e. $\bigcup A_{i}$ ). Unioning a set of (partially) overlapping polygons is a standard GIS procedure with the effect of merging their areas (Fig. 2d). Therefore, the difference between $\sum A_{i}$ and $\max \left(A_{\mathrm{i}}\right)$ represents the maximum distance possible $\left(\right.$ Dist $\left._{M A X}\right)$ from a perfectly 

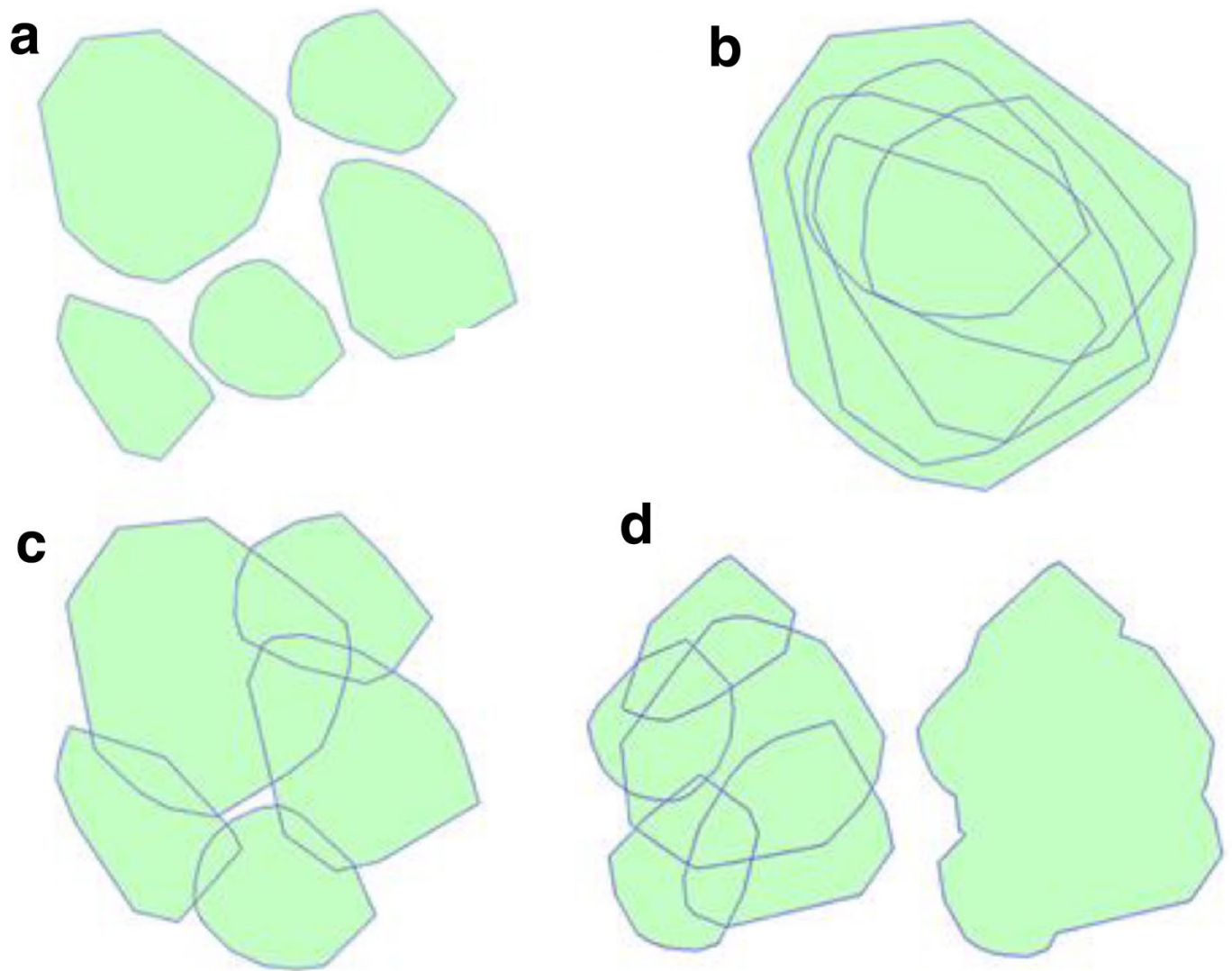

Fig. 2 a Perfectly disjoint (i.e., non-overlapping) home ranges, b perfectly nested (i.e., overlapping) home ranges, c partially-overlapping home ranges, $\mathbf{d}$ union (on the right) of partially-overlapping home range polygons (on the left)

non-overlapping situation. The difference between $\sum A_{i}$ and $\bigcup A_{i}$ is the observed distance (Dist ${ }_{O B S}$ ) from the perfectly disjoint situation. GOI was calculated as (Eq. 1):

$$
G O I=100 * \frac{\text { Dist }_{\mathrm{OBS}}}{\text { Dist }_{M A X}}=100 * \frac{\sum_{i=1}^{n} A_{i}-\bigcup_{i=1}^{n} A_{i}}{\sum_{i=1}^{n} A_{i}-\max \left(A_{i}\right)}
$$

where $n$ is the number of home ranges under study. GOI thus measures the distance of the observed overlaps from two extremes (perfect overlap and perfect non-overlap). If Dist $_{O B S}=0$, then $G O I=0$ (perfect non-overlap); if Dis$t_{O B S}=$ Dist $_{M A X}$, then $G O I=100$ (perfect overlap). If home ranges partially overlap, then $0<G O I<100$. The pseudocode of the algorithm used to calculate $G O I$ is described in the Additional file 2: Text S1.

Our overlap index corresponds, in essence, to the linear equation $Y=100 \times(b-X) /(b-a)$ where $a$ is the extent of the largest home range polygon, $b$ is the sum of the home range extents and $X$ is the extent of the union of home range polygons, which varies depending upon the degree of overlap. Since $b \geq X$ and $b>a$, then the denominator is always positive while the numerator can be positive or null. In addition, since $X \geq a$, then $b-X$ is always less than, or equal to, $b-a$. Thus GOI is constrained in the interval $[0,100]$, independently of the number of home ranges under study. In the case of perfectly non-overlapping home ranges, $X=b$ then $G O I=0$. In the case of perfectly overlapping home ranges, $X=a$ then $G O I=100$. Finally, a general segregation index $(G S I)$ was computed as the complement to 100 of GOI (Eq. 2):

$$
G S I=100-G O I=100 *\left(1-\frac{\sum_{i=1}^{n} A_{i}-\bigcup_{i=1}^{n} A_{i}}{\sum_{i=1}^{n} A_{i}-\max \left(A_{i}\right)}\right)
$$

The first derivatives of GOI and GSI (Eqs. 3, 4) show their rate of change with respect to $\bigcup A_{i}$ : 


$$
\frac{d G O I}{d \bigcup_{i=1}^{n} A_{i}}=\frac{-100}{\sum_{i=1}^{n} A_{i}-\max \left(A_{i}\right)}
$$

and

$$
\frac{d G S I}{d \bigcup_{i=1}^{n} A_{i}}=\frac{100}{\sum_{i=1}^{n} A_{i}-\max \left(A_{i}\right)}
$$

Therefore, every unitary increase/decrease (e.g. 1 ha if home ranges are expressed in hectares, $1 \mathrm{~km}^{2}$ if they are expressed in $\mathrm{km}^{2}$ ) of $\bigcup A_{i}$ determines a decrease/ increase in GOI, and a correspondent increase/decrease of GSI, equal to $\frac{100}{\sum_{i=1}^{n} A_{i}-\max \left(A_{i}\right)}$ (Additional file 2: Text S2).

We applied GOI to the individual and the colonyspecific home ranges, in order to estimate withincolony $\left(G O I_{\mathrm{W}}\right)$ and between-colony $\left(G O I_{\mathrm{B}}\right)$ overlaps respectively. As suggested by the "diplomacy" hypothesis (Grémillet et al. 2004), spatial segregation among nearby colonies may mitigate intraspecific competition for resources. In order to test this hypothesis, we used a randomization procedure to determine if $G O I_{\mathrm{B}}$ was greater than expected by chance. Under the null hypothesis of no spatial segregation between the two colonies, $\mathrm{GOI}_{\mathrm{B}}$ should not be significantly different from the size of the overlap if the GPS points of each colony were randomly and independently assigned. As Lesser Kestrels are central place foragers, distance is highly relevant and thus we could not assume they were free to visit all locations within the study area. Thus, we generated our null expectation by using a rotation with a random angle of the observed GPS points (by anchoring points to the coordinates of the correspondent urban colony), therefore randomly positioning the GPS points of each colony while keeping distances from the colony equal (Ferrarini et al. 2018a, b). In order to apply a rotational resampling of the colony data, all the data from each individual were randomly rotated around its nest location, independently from the other individuals. Mathematically, we used the standard algorithm (Eq. 5 and Eq. 6) for rotating points around a centre of rotation:

$$
\begin{aligned}
& x_{1}=\left(x_{0}-x_{\mathrm{c}}\right) \times \cos (\theta)-\left(y_{0}-y_{\mathrm{c}}\right) \times \sin (\theta)+x_{\mathrm{c}} \\
& y_{1}=\left(x_{0}-x_{\mathrm{c}}\right) \times \sin (\theta)+\left(y_{0}-y_{\mathrm{c}}\right) \times \cos (\theta)+y_{\mathrm{c}} .
\end{aligned}
$$

where $\left(x_{0}, y_{0}\right)$ is the point to be rotated, $\left(x_{\mathrm{c}}, y_{\mathrm{c}}\right)$ are the coordinates of the nest location, $\theta$ is the angle of rotation (positive counterclockwise), $\left(x_{1}, y_{1}\right)$ are the coordinates of point after rotation.
We then computed the randomly created home ranges $\left(H R_{\text {Rand }}\right)$ for each colony, and overlaps $\left(G O I_{\text {Rand }}\right.$ hereafter) between the two colonies. We repeated our randomizations 9999 times. The $P$-value for each colony was determined by the proportion of randomly created overlaps $G O I_{\text {Rand }}$ that were smaller than the observed overlap $\mathrm{GOI}_{\mathrm{B}}$.

\section{Results}

In total, we collected 24,074 GPS points, 11,993 at Cassano nelle Murge and 12,081 at Santeramo in Colle respectively (Table 1 ).

The five Lesser Kestrels of Cassano nelle Murge had an average home range size equal to $11,129.33$ ha $( \pm 6764.46$ std. dev.). The smallest and largest home ranges were 3802.39 ha (individual M6 C) and 21,142.96 ha (individual F6 C) respectively (Table 1). Pairwise percent overlaps (Table 2) ranged from $17.98 \%$ to $100 \%$, with an average value equal to $65.51 \%$ ( $\pm 27.64 \mathrm{std}$. dev.). Individual home ranges were almost completely nested within the largest home range (individual F6 C; Fig. 3), in fact $G O I_{\mathrm{W}}$ was equal to $96.41 \%$ (i.e., $\sum A_{i}=55,646.66$ ha; $\max \left(A_{\mathrm{i}}\right)=21,142.96 \mathrm{ha}$; $\left.\bigcup A_{i}=22,378.92 \mathrm{ha}\right)$, thus $G S I_{\mathrm{W}}$ was equal to $3.59 \%$ (Fig. 3 ).

The five Lesser Kestrels of Santeramo in Colle scored an average home range size equal to 6132.58 ha $( \pm 4026.29$ std. dev.). The smallest and largest home ranges were

Table 2 Pairwise percent overlap (in hectares and \%) between tracked Lesser Kestrels from Cassano delle Murge

\begin{tabular}{llcc}
\hline Individual A & Individual B & Overlap (ha) & Overlap (\%) \\
\hline F6C & M6C & 3802.39 & 17.98 \\
F6C & F12C & $13,263.67$ & 62.73 \\
F6C & F15C & 7166.23 & 33.89 \\
F6C & M15C & 8825.94 & 41.74 \\
M6C & F6C & 3802.39 & 100.00 \\
M6C & F12C & 3505.18 & 92.18 \\
M6C & F15C & 3451.19 & 90.76 \\
M6C & M15C & 2665.18 & 70.09 \\
F12C & F6C & $13,263.67$ & 92.59 \\
F12C & M6C & 3505.18 & 24.47 \\
F12C & F15C & 6805.01 & 47.50 \\
F12C & M15C & 8371.77 & 58.44 \\
F15C & F6C & 7166.23 & 98.11 \\
F15C & M6C & 3451.19 & 47.25 \\
F15C & F12C & 6805.01 & 93.17 \\
F15C & M15C & 4868.14 & 66.65 \\
M15C & F6C & 8825.94 & 97.29 \\
M15C & M6C & 2665.18 & 29.38 \\
M15C & F12C & 8371.77 & 92.28 \\
M15C & F15C & 4868.14 & 53.66 \\
\hline
\end{tabular}




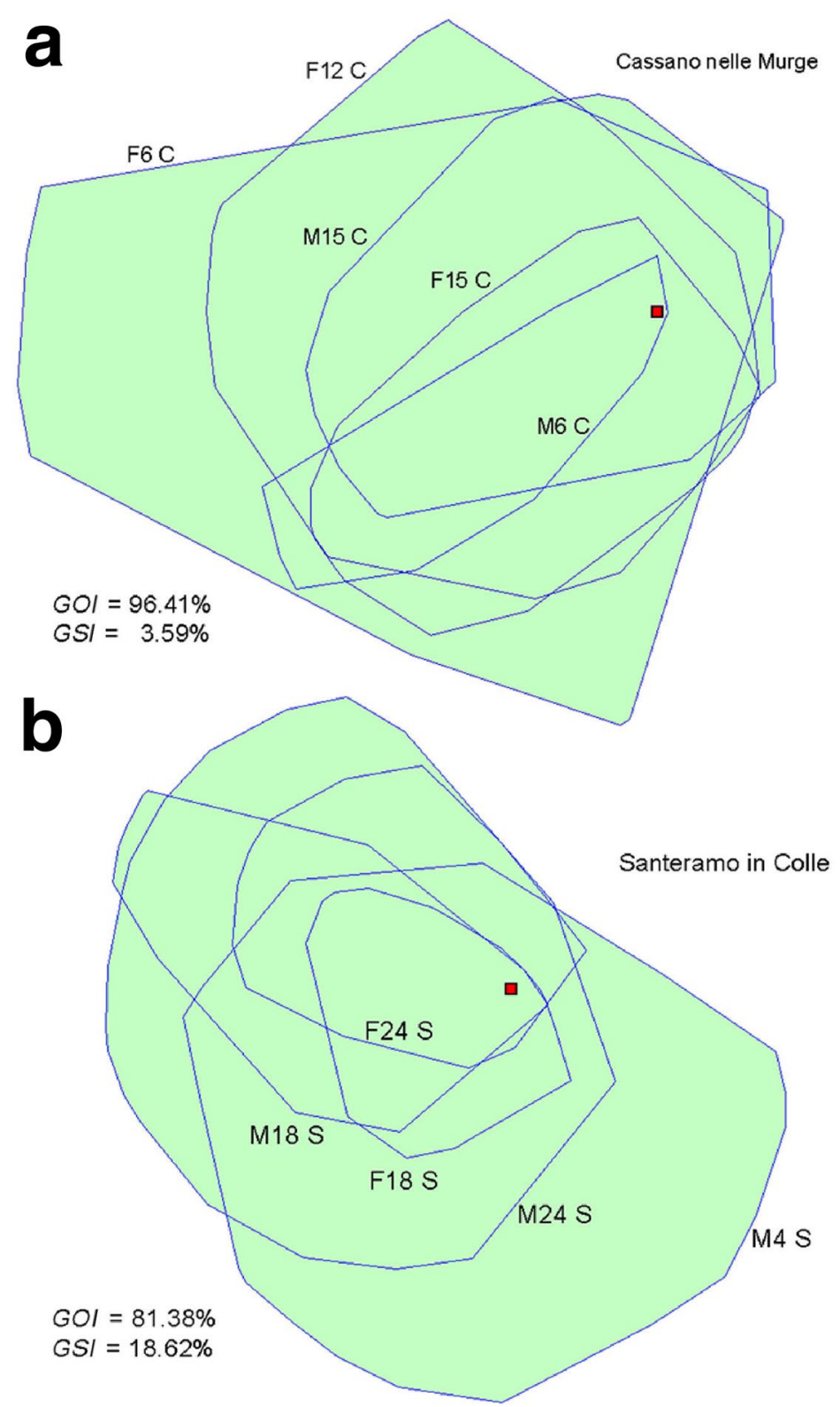

Fig. 3 Individual home ranges of the Lesser Kestrels tracked at Cassano nelle Murge (a) and Santeramo in Colle (b). See Table 1 for the GPS ID of the individuals. The red squares represent the towns of Cassano and Santeramo where the Lesser Kestrels have their nests. GOI and GSI stand for general overlap index and general segregation index, respectively

2275.81 ha (individual F18 S) and 11,147.12 (individual M4 S) ha respectively (Table 1). Pairwise percent overlaps (Table 3) ranged from $20.42 \%$ to $100 \%$, with an average value equal to $58.09 \%$ ( \pm 27.09 std. dev.). Individual home ranges were mostly nested within the home range of the second largest home range (individual M24 S), except for individual M4 S (Fig. 3). $G O I_{\mathrm{W}}$ was equal to $81.38 \%$ (i.e., $\sum A_{i}=30,662.86$ ha; $\max \left(A_{\mathrm{i}}\right)=11,147.12$ ha; $\left.\bigcup A_{i}=14,779.66 \mathrm{ha}\right)$, thus $G S I_{\mathrm{W}}$ was equal to $=18.62 \%$ (Fig. 3).

Colony-specific home ranges were 17,652.74 ha at Cassano and $13,228.31$ ha at Santeramo, respectively. Between-colony overlap was 2529.46 ha. $G O I_{\mathrm{B}}$ was equal to $19.12 \%$ (i.e., $\sum H R_{i}=30,881.05$ ha; $\max \left(A_{\mathrm{i}}\right)=17,652.74$ ha; $\bigcup A_{i}=28,351.58$ ha; Fig. 4), thus $G S I_{\mathrm{B}}$ was $80.88 \%$. The proportion of randomly created overlaps $G O I_{\text {Rand }}$ that were smaller than the observed 
Table 3 Pairwise percent overlap (in hectares and \%) between tracked Lesser Kestrels from Santeramo in Colle

\begin{tabular}{lllc}
\hline Individual A & Individual B & Overlap (ha) & Overlap (\%) \\
\hline M4S & F18 S & 2275.81 & 20.42 \\
M4 S & M18 S & 2793.65 & 25.06 \\
M4 S & F24 S & 2365.70 & 21.22 \\
M4 S & M24 S & 6214.35 & 55.75 \\
F18 S & M4 S & 2275.81 & 100.00 \\
F18 S & M18 S & 1749.35 & 76.87 \\
F18 S & F24 S & 1390.54 & 61.10 \\
F18 S & M24 S & 2275.81 & 100.00 \\
M18 S & M4S & 2793.65 & 69.05 \\
M18 S & F18 S & 1749.35 & 43.24 \\
M18 S & F24 S & 2224.76 & 54.99 \\
M18 S & M24 S & 3961.38 & 97.91 \\
F24 S & M4 S & 2365.70 & 68.94 \\
F24 S & F18 S & 1390.54 & 40.52 \\
F24 S & M18 S & 2224.76 & 64.83 \\
F24 S & M24 S & 3409.39 & 99.35 \\
M24 S & M4S & 6214.35 & 63.66 \\
M24 S & F18 S & 2275.81 & 23.31 \\
M24 S & M18 S & 3961.38 & 40.58 \\
M24 S & F24 S & 3409.39 & 34.92 \\
\hline
\end{tabular}

overlap $G O I_{\mathrm{B}}$ was $4.36 \%$ (436 randomizations out of 9999; $P=0.0436$ ), therefore the null hypothesis of no spatial segregation was rejected $(P<0.05)$.

\section{Discussion}

In this study, we have proposed a non-pairwise metric of home range overlap/segregation, and have applied it to two neighboring Lesser Kestrel's colonies in Southern Italy.

Our overlap index follows a simple idea: given $n$ home ranges, it is always possible to calculate the extent of two spatial configurations, perfect segregation and perfect overlap. In the former case (Fig. 2a), the extent covered by the home ranges is simply the sum of their areas, and in the latter case (Fig. 2b) it is equal to the area of the largest home range. Our index simply measures the distance of the observed overlaps from these two extremes. In doing so, our overlap index does not require calculating pairwise overlaps among individual home ranges. The uniquely non-pairwise nature of the metric leads to two interesting properties: first, it is computationally fast as it just requires the union of home range polygons (Fig. 2d) to be calculated within GIS; second, the overlap score provided by $G O I$ is semantically different from the overlap scores provided by pairwise overlap indices. In fact, GOI provides an estimate of how nested different home ranges areas are. This explains why in both colonies GOI did not duplicate the information provided by pairwise overlap measures (Tables 2, 3), and not even some statistical properties (e.g. mean or median) of such pairwise measures. In fact, mean pairwise overlap was $65.51 \% \pm 27.64$ (mean \pm std. dev.) at Cassano, and it was $58.09 \% \pm 27.09$ at Santeramo. Therefore, GOI was outside the mean \pm std. dev. interval at Cassano, and almost outside the right tail of the same interval at Santeramo. In addition, $G O I$ was much easier to interpret in comparison to the $5 \times 5$ pairwise overlap matrices (Tables 2, 3).

Our overlap index also has several other desirable properties: (1) GOI can be applied to an arbitrarily large number of home ranges (i.e., $n \geq 2$ ) belonging to individuals, populations (colonies) or species; (2) whatever the number of home ranges under study, GOI returns a single overlap measure; (3) in the case of perfectly disjoint home ranges, $\mathrm{GOI}$ is equal to 0 ; $(4)$ in the case of perfectly nested (overlapping) home ranges, $\mathrm{GOI}$ is equal to 100; (5) in any other case, GOI returns a value between 0 and 100; (6) GOI varies linearly between 0 and 100, independently of the number of home ranges under study. In fact, Eqs. 1-4 ensure that GOI and GSI and their rates of change are independent of (a) the number of observations and (b) the initial value assumed by $\bigcup A_{i}$, but only depend on the geometric and positional properties of the home ranges. The linear nature of these metrics also ensures that small/big changes to the home range overlaps proportionally determine small/big changes to $G O I$ (Additional file 2: Text S2).

In this study, we have applied GOI to 2D home ranges, however our overlap index can be readily applied to 3D home ranges as well (Tracey et al. 2014; Ferrarini et al. $2018 \mathrm{~b})$. In the case of volumetric home ranges, the $2 \mathrm{D}$ home range size should be simply replaced by $3 \mathrm{D}$ estimation, but GOI (and also GSI) would maintain the same properties described above. We estimated home ranges through the minimum convex polygons algorithm, however the application of GOI (and also GSI) is successive, and thus independent, of the type of algorithm (e.g. low convex hull; Getz et al. 2007) employed to assess birds' home ranges. Thus, both GOI and GSI can be applied to home range polygons derived from any type of home range estimator (Signer et al. 2015). We have applied GOI to a central-place forager, as this type of species presents elevated within-colony overlap thus making the use of an overlap index very appropriate. In the case of bird species 


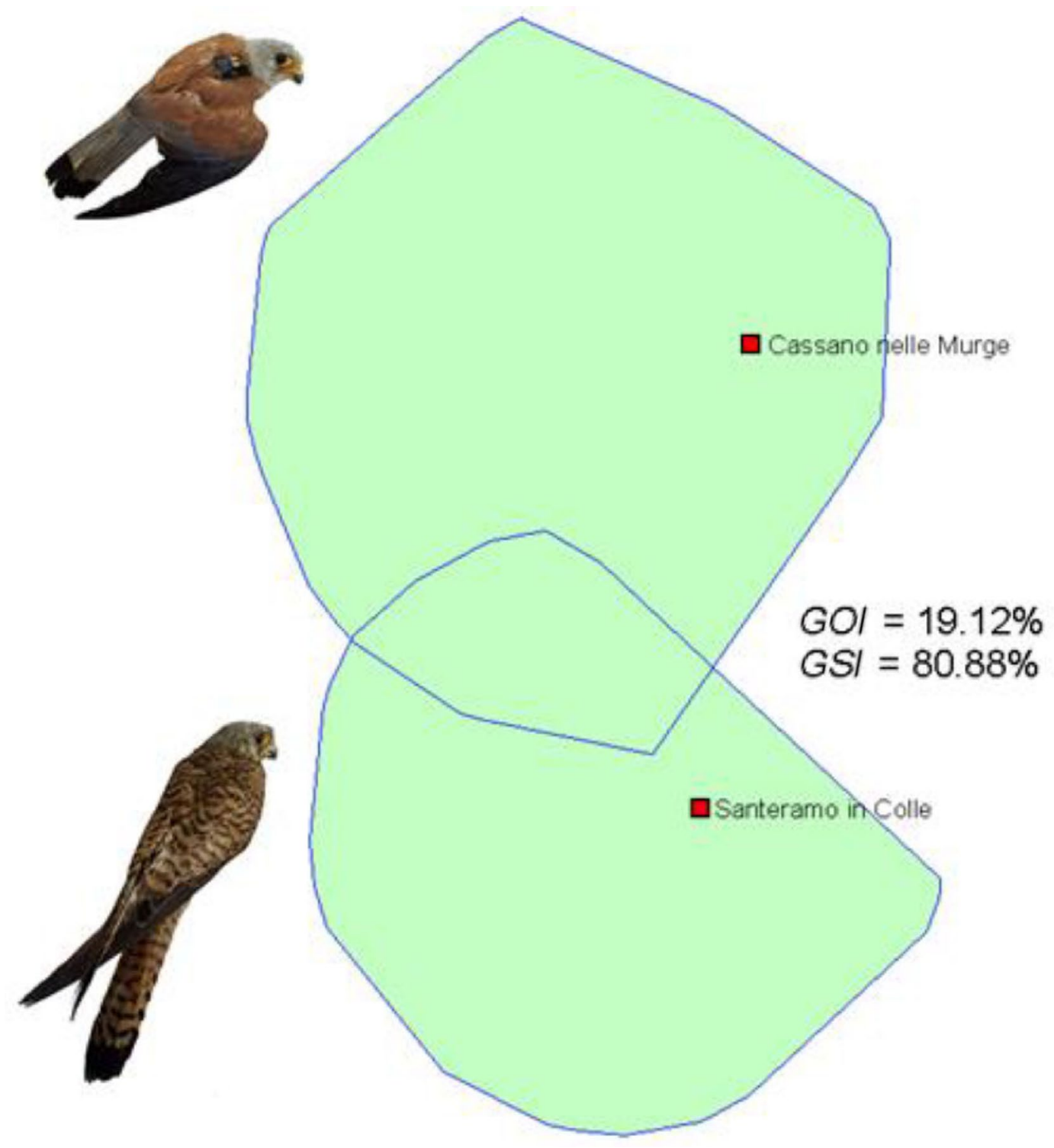

Fig. 4 Between-colony overlap. We first estimated colony-specific home ranges (i.e. home ranges calculated after pooling the locations of all individuals of each colony), then we calculated the between-colony overlap. The red squares represent the towns of Cassano and Santeramo where the Lesser Kestrels have their nests. GOI and GSI stand for general overlap index and general segregation index, respectively

with low overlaps, the alternative GSI index could be more suitable to readily assess the degree of home range segregation.

The populations studied here showed elevated intracolony overlap and between-colony segregation. These results are in agreement with findings from the nearby colonies of Gravina in Puglia and Altamura (Ferrarini et al. 2018a, b), although in that case segregation was computed using a standard pairwise overlap index. During the chick rearing interval the demand for food is the highest, thus this might affect spatial segregation between the colonies. By foraging in spatially segregated areas, individuals from different colonies may avoid interference competition for food (Grémillet et al. 2004). It is therefore plausible that spatial segregation is relaxed in other periods when food demand is lower.

\section{Conclusions}

Our overlap index addresses the question of generalizing pairwise measures of home range overlap to a single measure of overlap within or across populations or species. It is not intended to replace the commonly used 
pairwise approach, just represents a prompt measure of home range overlap/segregation, which is particularly useful when the number of home ranges to be analyzed is elevated. As home range overlap/segregation is an ecologically significant property of animal space use and interactions, GOI can be useful to promptly summarize ecological information from a set of home ranges estimated at individual, population or species level, and readily formulate working hypotheses and address successive analyses. Real-life applications of this metric can include (a) measuring intra-specific competition during the breeding season, (b) detecting change in space use over successive years, (c) evaluating degree of competition among various age classes, and (d) evaluating the reliability of home-range assessment by measuring the degree of overlap of several estimators.

\section{Supplementary Information}

The online version contains supplementary material available at https://doi. org/10.1186/s40657-020-00240-7.

Additional file 1: Figure S1. Field work. Figure S2. Some artificial nests used by Lesser Kestrels in 2017. Figure S3. GPS loggers. Figure S4. GPS deployment.

Additional file 2: Text S1. The pseudo-code used to calculate the General Overlap Index and the General Segregation Index of $n$ home ranges. Text S2. The mathematical behaviors of the General Overlap Index and the General Segregation Index.

\section{Acknowledgements}

We thank Annagrazia Frassanito (Alta Murgia National Park) for project administration. We thank three anonymous reviewers for their useful remarks and suggestions that improved this manuscript.

\section{Authors' contributions}

AF conceived the study; GG, MG, SCP participated in the field work; AF carried out the GIS and modelling work; AF, MG drafted the earlier version of the manuscript, and GG, SCP revised it. All authors read and approved the final manuscript.

\section{Funding}

This work was supported by LIPU-UK (GIS and modelling work) and by the Alta Murgia National Park (biotelemetry and field work).

\section{Availability of data and materials}

The datasets used in the present study are available from the corresponding author on reasonable request.

\section{Ethics approval and consent to participate}

Our research adheres to local guidelines and appropriate ethical approval and licences were obtained.

\section{Consent for publication}

Not applicable.

\section{Competing interests}

The authors declare that they have no competing interests.

Received: 30 July 2020 Accepted: 15 December 2020

Published online: 05 January 2021

\section{References}

Adams ES. Approaches to the study of territory size and shape. Annu Rev Ecol Syst. 2001:32:277-303.

BirdLife International. Species factsheet: Falco naumanni. 2017.

Brown JL, Orians GH. Spacing patterns in mobile animals. Annu Rev Ecol Syst. 1970;1:239-62.

Clay TA, Manica A, Ryan PG, Silk JRD, Croxall JP, Ireland L, et al. Proximate drivers of spatial segregation in non-breeding albatrosses. Sci Rep. 2016;6:29932.

Davies NB. Ecological questions about territorial behaviour. In: Krebs JR, Davies NB, editors. Behavioural ecology, an evolutionary approach. Oxford: Blackwell Scientific Publications; 1978. p. 317-50.

Ferrarini A, Giglio G, Pellegrino SC, Frassanito A, Gustin M. First evidence of mutually exclusive home ranges in the two main colonies of Lesser Kestrels in Italy. Ardea. 2018a;106:85-9.

Ferrarini A, Giglio G, Pellegrino SC, Frassanito A, Gustin M. A new methodology for computing birds'3D home ranges. Avian Res. 2018b;9:19.

Ferrarini A, Giglio G, Pellegrino SC, Frassanito A, Gustin M. Behavioural Networks: a new methodology to study birds habits. Netw Biol. 2019;9:1-9.

Fieberg J, Kochanny CO. Quantifying home-rangeoverlap: the importance of the utilization distribution. J Wild life Manage. 2005:69:1346-59.

Getz WM, Fortmann-Roe S, Cross PC, Lyons AJ, Ryan SJ, Wilmers CC. LoCoH: Nonparameteric kernel methods for constructing home ranges and utilization distributions. PLoS ONE. 2007;2:e207.

Grémillet D, Dell'omo G, Ryan PG, Peters G, Ropert-Coudert Y, Weeks SJ. Offshore diplomacy, or how seabirds mitigate intra-specific competition: a case study based on GPS tracking ofCape gannets from neighbouring colonies. Mar Ecol Prog Ser. 2004;268:265-79.

Gustin M, Ferrarini A, Giglio G, Pellegrino SC, Scaravelli D. II Parco per il Grillaio (Falco naumanni) nel Parco Nazionale dell'alta Murgia Technical relation 2013. Italy: Lipu Press; 2013.

Gustin M, Ferrarini A, Giglio G, Pellegrino SC, Frassanito A. Detected foraging strategies and consequent conservation policies of the Lesser Kestrel Falco naumanni in Southern Italy. Proc Int Acad Ecol Environ Sci. 2014a;4:148-61.

Gustin M, Ferrarini A, Giglio G, Pellegrino SC, Frassanito A. First evidence of widespread nocturnal activity of Lesser Kestrel Falco naumanni in Southern Italy. Ornis Fenn. 2014b;91:256-60.

Gustin M, Giglio G, Pellegrino SC, Frassanito A, Ferrarini A. Space use and fight attributes of breeding Lesser Kestrels Falco naumanni revealed by GPS tracking. Bird Study. 2017a;64:274-7.

Gustin M, Giglio G, Pellegrino SC, Frassanito A, Ferrarini A. New evidences confirm that during the breeding season Lesser Kestrel is not a strictly diurnal raptor. Ornis Fenn. 2017b;94:194-9.

Gustin M, Giglio G, Pellegrino SC, Frassanito A, Ferrarini A. Nocturnal fights lead to collision risk with power lines and wind farms in Lesser Kestrels: a preliminary assessment through GPS tracking. Comput Ecol Softw. 2018;8:15-22

Kenward R. Wildlife radio tagging. London: Academic Press Inc.; 1987. Kernhoan BJ, Gitzen RA, Millspaugh JJ. Analysis of animal space use and movements. In: Millspaugh JJ, Marzluff JM, editors. Radio tracking animal populations. San Diego: Academic Press; 2001. p. 125-66.

Lascelles BG, Taylor PR, Miller MGR, Dias MP, Oppel S, Torres L, et al. Applying global criteria to tracking data to define important areas for marine conservation. Divers Distrib. 2016;22:422-31.

Macias-Duarte A, Panjabi AO. Home range and habitat use of wintering vesper sparrows in grasslands of the Chihuahuan desert in Mexico. Wilson J Ornithol. 2013;125:755-62.

Newton I. Population limitation in birds. London: Academic Press Inc.; 1998.

Signer J, Blakenhol N, Ditmer M, Fieberg J. Does estimator choice influence our ability to detect changes in home-range size? Anim Biotelemetry. 2015;3:16.

Tracey JA, Sheppard J, Zhu J, Wei F, Swaisgood RS, Fisher RN. Movement-based estimation and visualization of space use in 3D for wildlife ecology and conservation. PLoS ONE. 2014;9:e101205.

Wang K, Franklin SE, Guo X, Cattet M. Remote sensing of ecology, biodiversity and conservation: a review from the perspective of remote sensing specialists. Sensors. 2010;10:9647-67. 
Warning $\mathrm{N}$, Benedict L. Overlapping home ranges and microhabitat partitioning among Canyon Wrens (Catherpes mexicanus) and Rock Wrens (Salpinctes obsoletus). Wilson J Ornithol. 2015;127:395-401.

White GC, Garrott RA. Analysis of wildlife radio-tracking data. San Diego: Academic Press; 1990
Yang N, Zhang K, Lloyd H, Ran J, Xu Y, Du B, et al. Group size does not influence territory size and overlap in a habituated population of a cooperative breeding Himalayan Galliforme species. Ardea. 2011;99:199-206.

Zhao M, Cao L, Klaassen M, Zhang Y, Fox AD. Avoiding competition? Site use, diet and foraging behaviours in two similarly sized geese wintering in China. Ardea. 2015;103:27-38.
Ready to submit your research? Choose BMC and benefit from:

- fast, convenient online submission

- thorough peer review by experienced researchers in your field

- rapid publication on acceptance

- support for research data, including large and complex data types

- gold Open Access which fosters wider collaboration and increased citations

- maximum visibility for your research: over $100 \mathrm{M}$ website views per year

At BMC, research is always in progress.

Learn more biomedcentral.com/submissions 